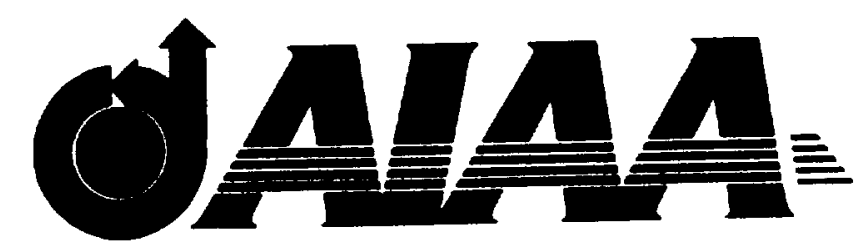

AIAA-2001-0755

Status of the National Transonic Facility

Characterization (Invited)

C. Bobbitt, Jr., J. Everhart

NASA Langley Research Center

Hampton, Virginia

39th AIAA Aerospace Sciences Meeting \& Exhibit

$$
\begin{aligned}
& \text { 8-11 January } 2001 \\
& \text { Reno, Nevada }
\end{aligned}
$$





\title{
Status of the National Transonic Facility Characterization
}

\author{
C. Bobbitt, Jr., J. Everhart \\ Aerodynamics, Aerothermodynamics, and Acoustics Competency \\ NASA Langley Research Center \\ Hampton, Virginia
}

\begin{abstract}
This paper describes the current activities at the National Transonic Facility to document the test-section flow and to support tunnel improvements. The paper is divided into sections on the tunnel calibration, flow quality measurements, data quality assurance, and implementation of wall interference corrections.
\end{abstract}

Facility

\section{INTRODUCTION}

The NTF was primarily designed to achieve flight-Reynolds numbers at transonic speeds using a combination of high pressures and cryogenic temperatures. It is a closed-circuit tunnel with a single-stage compressor, a 15:1 contraction ratio, and a 25-foot long, 8.2-foot square test-section with filleted corners. The test-section can be run in a slotted-wall (top and bottom walls slotted with a 6-percent openness ratio) or a solidwall configuration. Figure 1 shows a layout of the tunnel, with the nitrogen injection ring between turns 1 and 2, the inlet guide vanes, fan, and stators between turns 2 and 3 , and the heat exchanger and four turbulence reduction screens in the settling chamber just upstream of the contraction region. Tunnel specifications are given in Table 1. The tunnel can be run with either air or nitrogen as the test-medium. In the air mode, temperature control is achieved using a water-filled heat exchanger; in the nitrogen mode, temperature control is achieved by the injection of liquid nitrogen into the flow. Mach number control is achieved using a combination of selected fan speed and inlet guide vane angles. The NTF can test stingmounted full-span models or sidewallmounted semi-span models.

\section{Tunnel Characterization}

The purpose of a wind tunnel is to provide high-quality aerodynamic data. To do so "we must determine the required accuracy in measurements; translate these requirements into requirements on the flow field; determine if the tunnel flow meets these requirements; and determine the impact and possible solutions if the flow field does not meet these requirements." 1 The NTF characterization effort was designed to address these five issues. The first three issues can be classified as documentation of the tunnel characteristics. The last two issues can be classified as understanding and improving the tunnel characteristics. Additionally, this effort seeks to develop and implement new

- Test-section area:

$8.2 \mathrm{ft} . \times 8.2 \mathrm{ft}$

- Test-section length:

$25 \mathrm{ft}$.

- Mach range:

0.10 to 1.2

- Pressure range (psia): 15 to 125

- Temperature range $(F):-250$ to 120

- Max Reynolds number 146 million / ft. at Mach $=1.0$

\section{Table 1 - NTF Specifications}

Copyright (C) 2001 by the American Institute of Aeronautics and Astronautics, Inc. No copyright is asserted in the United States under Title 17, U. S. Code. The U. S. Government has a royalty-free license to exercise all rights under the copyright claimed herein for Governmental Purposes. All other rights are reserved by the copyright owner. 
ideas and test techniques to reduce the time and expense of characterizing the tunnel.

The previous overview focused on the documentation aspect of the characterization. This overview focuses more on the understanding and improvements to the tunnel flow, and improvements to the characterization processes. Since much of the analysis is in progress, the emphasis is on the work being done, rather than results from completed tasks.

To facilitate strategic planning, the facility characterization is divided into the following four areas: tunnel calibration, flow quality measurements, statistical quality control, and implementation of wall interference correction techniques. The status of each area follows.

\section{TUNNEL CALIBRATION}

Results from the most recent solid- and slotted wall calibrations were presented in reference 1 . This information is currently being used to correct the measured reference Mach number to the test-section centerline value, and to determine the buoyancy drag corrections due to the longitudinal Mach number gradient. Also presented in reference 1 is the accuracy of the Mach number correction. While this is usually the extent to which calibration data are used, much can still be learned from the existing data, including

- optimizing the calibration test-matrix for future calibrations, reducing the time and cost of a calibration

- determining the best way to quantify the variation in the longitudinal Mach number gradient

- comparing the solid- and slotted-wall calibrations to see if the basic character of the test-section flow is similar for the two configurations, thereby gaining a better understanding of the tunnel

- determining if wall pressure measurements can be used for calibrations instead of measurements made with a centerline pipe, reducing the duration and cost of a calibration.

The current focus is to minimize and improve the calibration process. An effort is underway to implement a Modern Design of Experiments approach to characterize the wall pressure orifice signatures ${ }^{2}$. If successful, this approach can be applied to tunnel Mach number calibrations, as well.

\section{FLOW QUALITY MEASUREMENTS}

This past year, several efforts in the area of flow quality were initiated. These efforts are described below.

\section{Fluctuating pressure measurements}

Fluctuating pressure measurements were made to determine the effect on the flow quality of the tunnel structural modifications described in reference 3. These measurements were made using 5-psid pressure transducers, mounted on the tunnel sidewall centerline four feet aft of the model center-of-rotation location (labeled Station 17). The signals were low-pass filtered at $160 \mathrm{~Hz}$. Figure 2 shows the root-meansquare (RMS) fluctuating pressure values, normalized by test-section dynamic pressure, as a function of Mach number both before and after the tunnel structural modifications. All of the measurements made over a range of Reynolds numbers for both warm and cryogenic tunnel conditions are plotted. The results show roughly a $20 \%$ reduction (from 0.005 to 0.004 ) in the maximum fluctuating pressure at transonic speeds at this test-section location. Also seen in the figure is a rise in the fluctuating pressure below a Mach number of 0.20 . The cause of this rise is not known, and is currently being investigated.

\section{Temperature distributions}

During a tunnel maintenance period this past summer, the cast iron piping supplying cooling water to the tunnel heat exchanger was replaced with stainless steel piping. This effort required a re-balancing of the heat exchanger. In the heat exchanger the supply water is routed through sets of finned-tubes, with the flow to each set of tubes being controlled by an individual valve. Balancing of the heat exchanger consists of adjusting 
these flow control valves until a uniform (air) temperature distribution is achieved in the tunnel. The temperature distribution is measured with a grid of thermocouples located in the tunnel settling-chamber just downstream of the heat exchanger. Figure 3 shows the approximate locations of these thermocouples. Measurements were first made with all of the flow control valves set in the full-open position. The subsequent temperature measurements showed that the temperature distribution was similar before and after the piping modifications. This comparison of the measurements is shown in Figure 4 , with the measurements broken down into the top, middle, and bottom rows of thermocouples. The fact that the temperature distribution is similar even though the flow control valve positions were different indicates that the flow through the heat exchanger piping is relatively insensitive to the valve positions. This situation is caused by debris in the tubes (from the replaced cast iron piping), inhibiting the flow of the cooling water.

Recently, burst tubes have been found in the heat exchanger. These leaks have been identified either by the appearance of water in the tunnel or by the loss of pressure during a standard pressure check of the heat exchanger. The heat exchanger is, by procedure, drained and purged before switching to nitrogen operations to remove any water. However, if the tubes are clogged, as some have been shown to be, water can be trapped in the tubes and they may burst when the tunnel operates below 32 deg. $F$.

In the last few months, an examination of the heat exchanger piping internal to the tunnel found many pipes partially or completely blocked. While these pipes were cleaned out, it is almost certain that there still exist other areas of restricted flow in the heat exchanger. A current study is underway to provide a plan to repair the heat exchanger and return it to its original operational condition.

\section{Moisture/Frost Contro}

Since the NTF operates at cryogenic conditions, it is more susceptible to problems with moisture than traditional wind tunnels. Very small amounts of water in the tunnel can condense and freeze on the model in the form of frost. The frost is usually first seen in areas of low pressure (and therefore lower temperature) such as the leading edge of wings, or areas of vortical flow. Any frost on the model brings into question the quality of data being obtained. Therefore, the NTF has recently implemented a policy that no research data will be taken if frost is suspected on a test-article.

Frost has been more apparent on recent tests than in the past history of the NTF. Part of this is attributable to the leaks in the heat exchanger described earlier. However, the suspected main source for introducing moisture in the tunnel occurred on a recent semi-span test. The NTF is configured to allow access to a sting-mounted model while the tunnel circuit is held at cryogenic conditions. However, a similar semi-span access system does not currently exist (although the design for this access system exists, and is planned to be implemented). To make a model change, the entire circuit must be warmed, and the test-section opened for access. Previous criteria for conditioning the tunnel has been based on personnel requirements. Subsequently, the criteria required the tunnel structure in the area of model access to be warmed, but allowed cold temperatures to exist in other parts of the tunnel circuit. When these parts of the tunnel were exposed to air with a dew point below the structural temperature, water or frost would condense onto the structure. This moisture would then eventually find its way into the tunnel insulation, which is located between the pressure shell and the flow surface. This problem was exacerbated on the semi-span test because quick access was made to the model to promote productivity. This process resulted in structural temperatures being lower than previously experienced during tunnel accesses, causing moisture to condense in the tunnel circuit. 

classical methods to a national standard. The first phase of the program is designed to establish wind tunnel data credibility and to implement the required codes and analysis tools. The second phase is directed toward validation of the correction methods and toward establishing uncertainty bands about the predicted correction increment. Here, data are acquired on multiple models tested in multiple test section geometries, including both solid and slotted wall configurations.

Experimentally, the modern methods differ from the classical methods in that they require additional boundary information at the wall (typically, pressure signatures) in addition to the traditional test conditions, forces and moments, and model information, such as shape, attitude, and position. The proper procedure-based use of the measurement systems combined with statistical tracking methods allows an uncertainty statement to be attached to data. Theoretically, this approach requires documented, standardized methods, such as the Wall Interference Correction System (WICS) code $^{8.13}$ for solid wall test sections and the PANCOR code $e^{9,10}$ for slotted walls.

Considerable progress has been made over the past year regarding data credibility. In addition to the ongoing Data Quality Assurance (DQA) program ${ }^{7}$, the wall pressure data system (WPDS) has been significantly enhanced. These enhancements include refurbishing those orifices yielding questionable measurements and the installation of additional wall orifices, bringing the total to about 470 pressure ports in 18 active rows spaced around the test section periphery. Tubing to the pressure orifices has been replaced and shortened to reduce response time. Test procedures regarding wall ESP calibrations have been formalized and, importantly, the configuration of the WPDS has been placed under procedural control. A first step at characterizing the wall pressure signature using Modern Design of Experiments methodology has been taken and this activity is reported in reference 2 .

The NTF implementation of the WICS code for solid wall testing has been reported in reference 8 . To date, the code has been applied to three different NTF test models. The first is the generic, full-span Pathfinder I transport model used to provide implementation data. This model has a wingreference-area to tunnel-cross-section area $\left(S / A_{T}\right)$ of 0.0300 . Since this model is also used as the facility check standards model, interference corrections can be monitored periodically as part of the ongoing DQA process. The other two tests used a large $\left(S / A_{T}=0.0988\right)$, low-aspect-ratio wing model (LARW) and a large ( $\left.S / A_{T}=0.0926\right)$, highaspect-ratio wing model (HARW). Each of these models was tested at $M_{\infty}=0.20$. Very encouraging results for the LARW model were previously presented in reference 1 , and they are again presented in Figure 6. Force and moment data corrected with WICS and also using classical methods ${ }^{4.6 .12}$ compare favorably with uncorrected data acquired in the slotted wall test section. Further discussions of the LARW data set are presented by Luckring".

A more severe test of the method is demonstrated in Figure 7 using results from the HARW model. Aerodynamic data on this model were acquired well beyond stall and, as indicated, are in exceptionally good agreement with the uncorrected slotted wall data over the range of the test conditions. Taken together, these two large-model demonstrations provide credible evidence regarding the validity of the theory for these conditions; however, insufficient data are currently available to establish uncertainty bands about the correction predictions. Postpoint implementation of this code is presently underway.

Walker recently addressed the strong linkage between data credibility and the theoretical predictions of the WICS code ${ }^{14}$. This work had two major objectives: first, determine WICS code output sensitivity to measurement uncertainty; and, second, establish operational guidelines for the instrumentation. The analysis indicated the WICS code to be relatively insensitive to random error in the wall pressures when the number of orifices exceeds 150 , because the solution method uses a global least-squaresfitting procedure. The analysis also indicated 
a strong sensitivity to systematic error in the wall pressures. Blockage error predictions vary directly with systematic error. Since tunnel blockage also varies directly with Reynolds number variations, pseudoReynolds number effects can be introduced if data are not corrected for wall effects. Conversely, systematic error in the wall pressures can also introduce pseudoReynolds number effects even if the data are corrected for wall effects. Walker, Everhart, and lyer present further discussion and results in reference 15.

As a side benefit, solid wall testing can provide significant cost reductions for many conditions compared to testing with slotted walls. It is estimated using reference 5 that a 6-percent-open slotted-wall tunnel at Mach 0.7 uses $30 \%-40 \%$ more power than comparable tests with solid walls. Specifically, the Mach 0.2 slotted wall data presented in Figure 7 required a 15\% power increase. The potential for even greater cost reductions occurs during cryogenic operations where nitrogen usage is directly proportional to power utilization. Credible wall interference corrections can enable large model tests in solid wall test sections and significantly reduce the cost of this type of test.

\section{CONCLUDING REMARKS}

Much progress has been made with respect to the characterization of the NTF. The use of Modern Design of Experiments for characterization tests holds promise for reducing the duration and cost of tests, while also allowing easier analysis of the results. Recent tunnel structural modifications have resulted in the test-section fluctuating pressure levels being reduced by $20 \%$ at transonic conditions, and solutions to the problems of tunnel moisture and flow angle variation are being developed and implemented. Check-standard model and probe tests supporting the statistical quality assurance initiative continue, and implementation and verification of solid-wall wall interference correction methods is progressing well.

\section{REFERENCES}

1. Bobbitt, C., Everhart, J., Foster, J., Hill, J.; McHatton, R., and Tomek, B., "National Transonic Facility Characterization Status," AIAA 2000293, January 2000.

2. Underwood, Pamela J., Everhart, Joel L., and DeLoach, Richard, "National Transonic Facility Wall Pressure Calibration Using Modern Design of Experiments," AIAA 2001-0171, January 2001.

3. Kilgore, W. Allen, Balakrishna, S., and Butler, D., "Reduction of Tunnel Dynamics at the U.S. National Transonic Facility," AIAA 2001-1162, January 2001.

4. Ewald, B. F. R. (Editor), "Wind Tunnel Wall Correction," AGARDograph 336, October 1998.

5. Goethert, Bernhard H., "Transonic Wind Tunnel Testing." Edited by Wilbur $\mathrm{C}$. Nelson. AGARDograph 49. Pergamon Press, 1961.

6. Hackett, J. E., "Tunnel-Induced Gradients and Their Effect on Drag," Lockheed Georgia Co., Lockheed Engineering Rept. LG83ER0108 Revision 1, Marietta GA, September 1994.

7. Hemsch, M. J., "Langley Wind Tunnel Data Quality Assurance - Check Standards Results (Invited)," AIAA 20002201, June 2000.

8. lyer, V., Everhart, J. L., Bir, P. J., and Ulbrich, N., "Implementation of the WICS Wall Interference Correction System at the National Transonic Facility," AIAA 2000-2383, June 2000.

9. Kemp, W. B., Jr., "Computer Simulation of a Wind Tunnel Test Section with Discrete Finite-Length Wall Slots," NASA CR-3948, 1986. 
10. Kemp, W. B., Jr., "Users Guide to PANCOR: A Panel Method Program for Interference Assessment in Slotted-Wall Wind Tunnels," NASA CR-187479, 1990.

11. Luckring, J, and Ghee, T., "Subsonic Reynolds Number Effects on a Diamond Wing Configuration (Invited)," AIAA 2001-0907, January 2001.

12. Maskell, E. C., "A Theory of Blockage Effects on Bluff Bodies and Stalled Wings in a Closed Wind Tunnel," R\&M 3400, November 1963.
13. Ulbrich, N., "The Real-Time Wall Interference Correction System of the NASA Ames 12-Foot Pressure Tunnel," NASACR-1998-208537, July 1998.

14. Walker, Eric Lee, "Sensitivity of the Wall Interference Correction System to Measurement Uncertainty," Master's Thesis, The George Washington University, August 2000.

15. Walker, Eric L., Everhart, Joel L., lyer, Venkit, "Sensitivity Study of the Wall Interference Correction System (WICS) for Rectangular Tunnels," AIAA 2001. 0159, January 2001. 


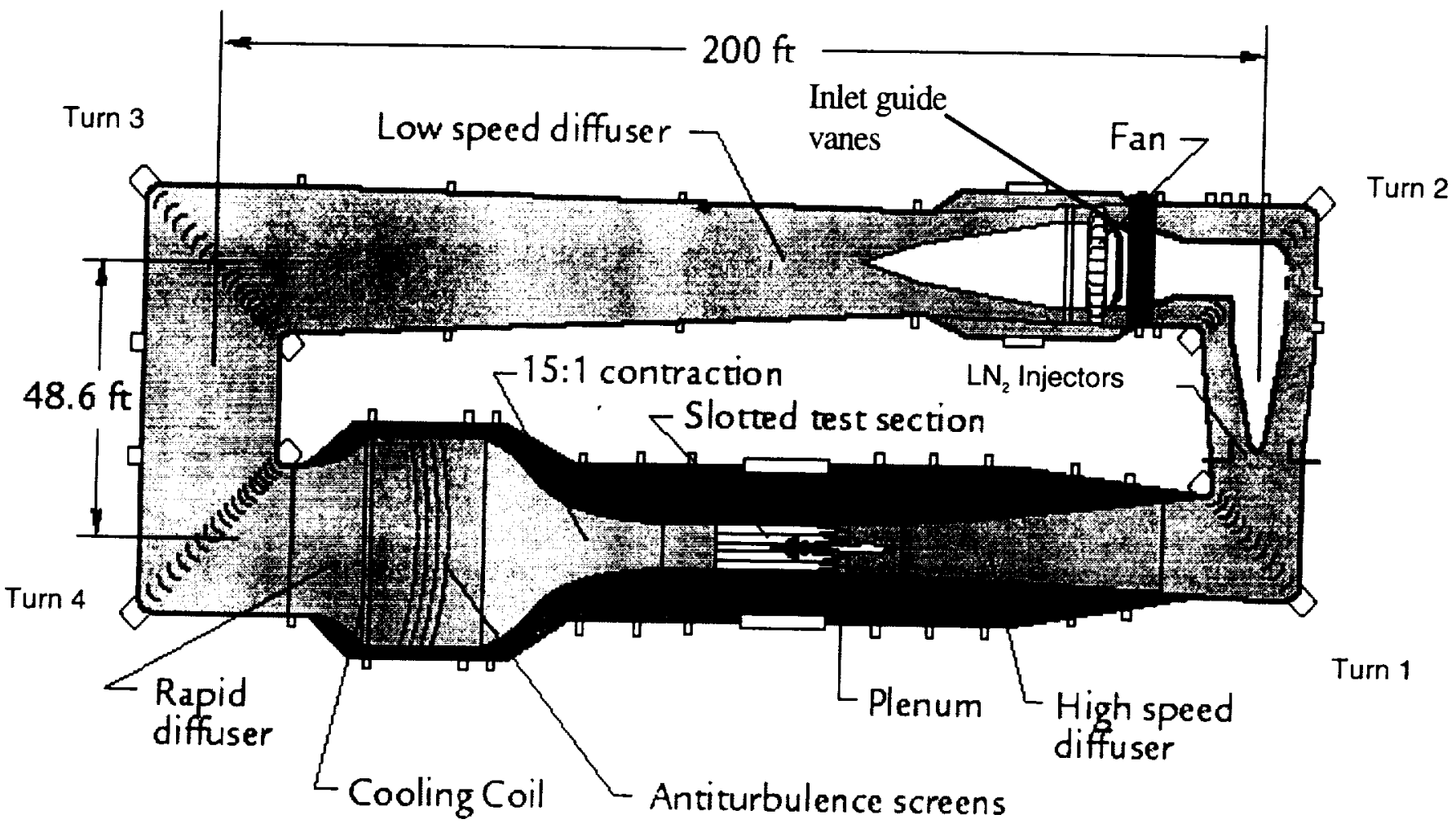

Figure 1-Layout of the NTF Circuit 

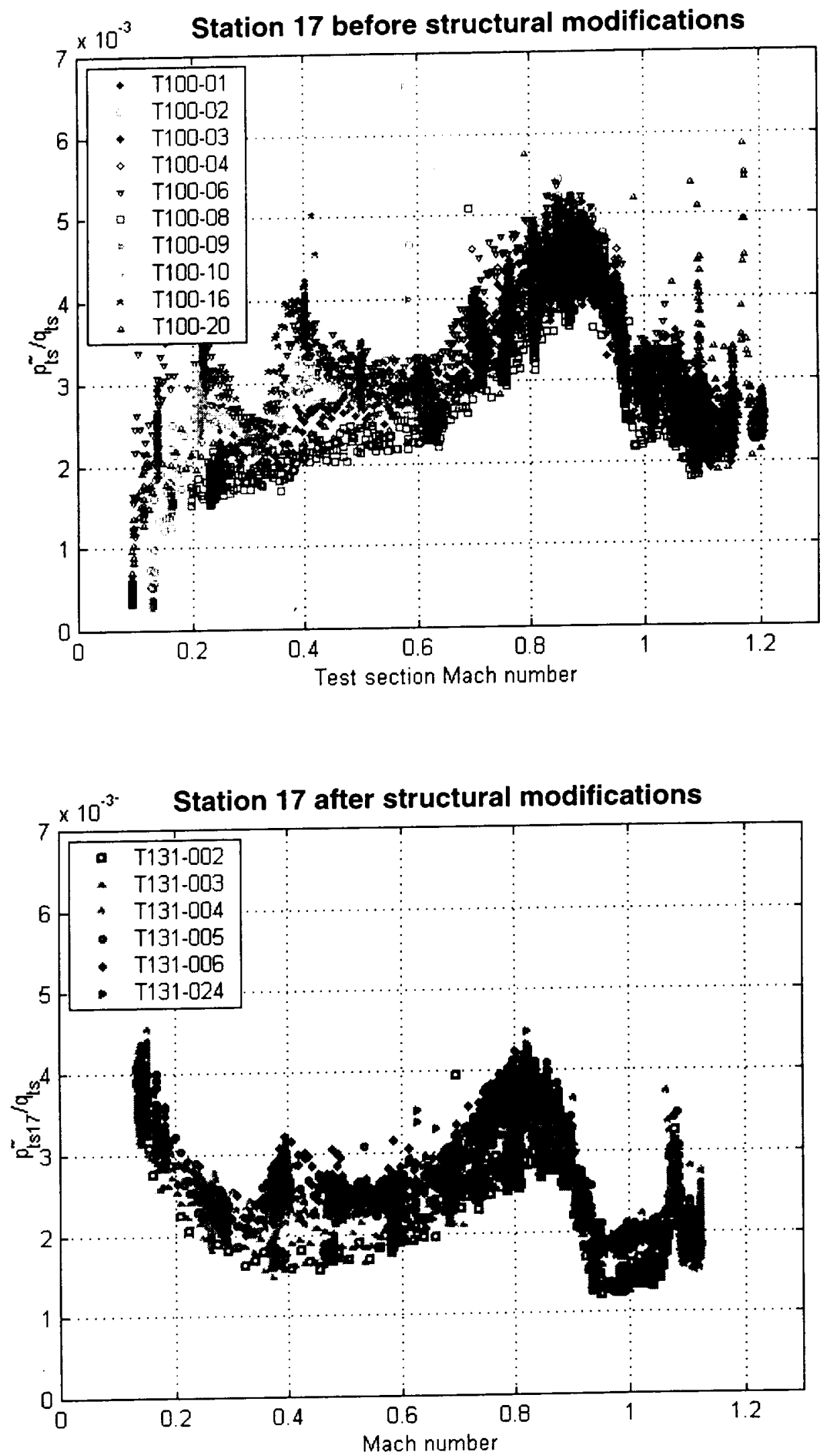

Figure 2 - Fluctuating pressure levels before and after tunnel structural modifications 


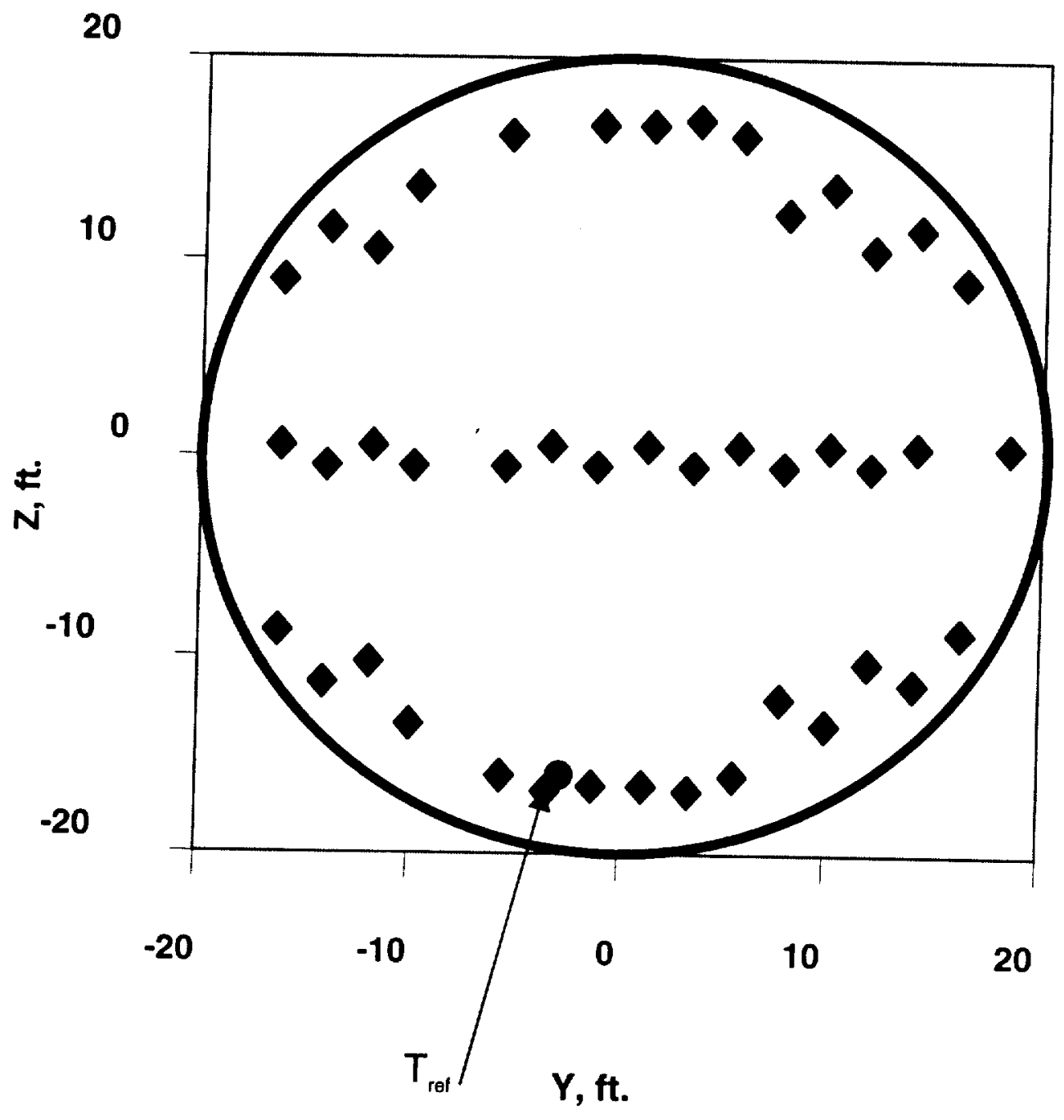

Figure 3 - Settling Chamber Thermocouple Layout (Looking Downstream) 
After Modifications

Top Row

Prior to Modifications
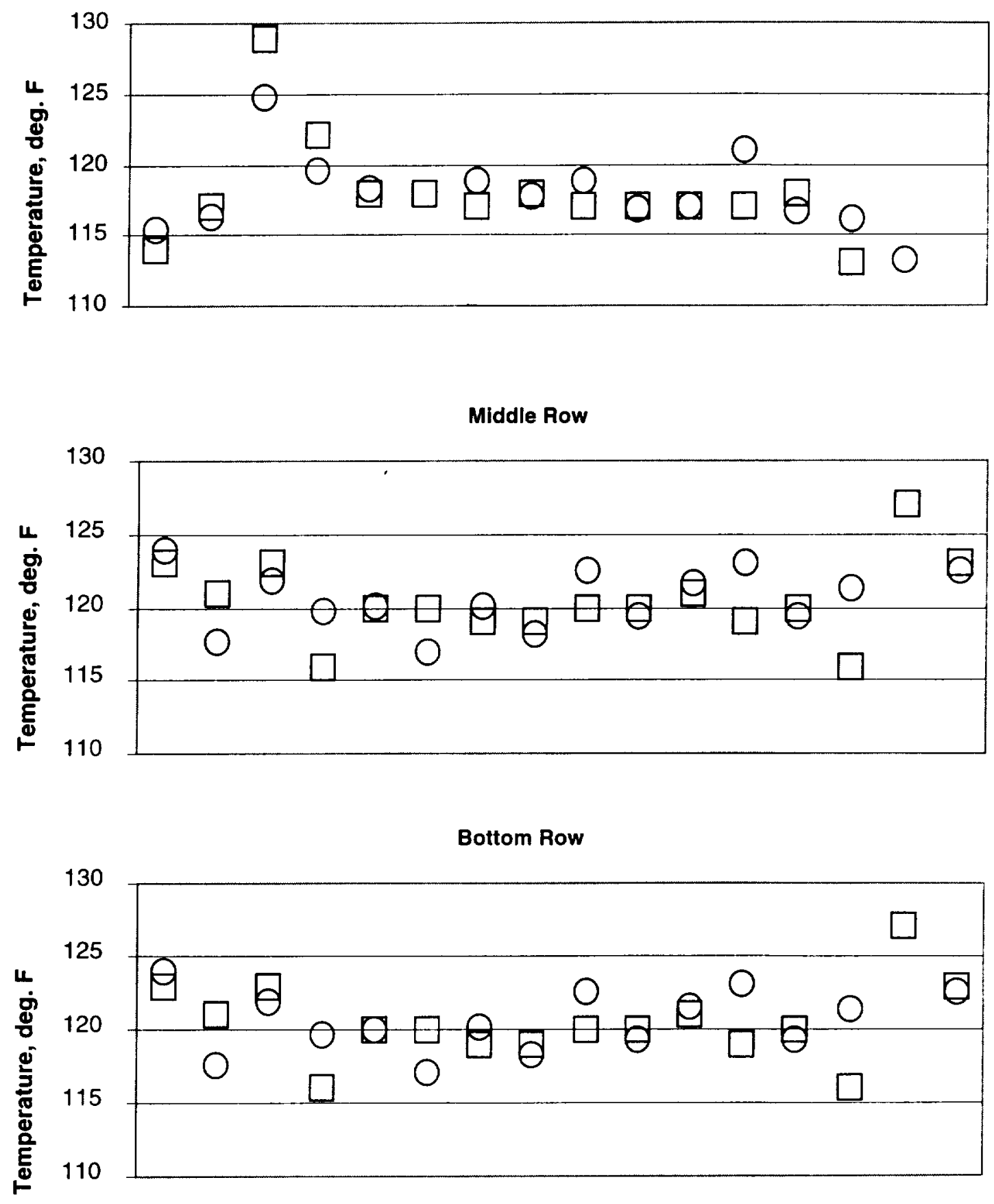

Figure 4 - Settling-chamber temperature distribution before and after heat exchanger piping modifications (looking downstream) 


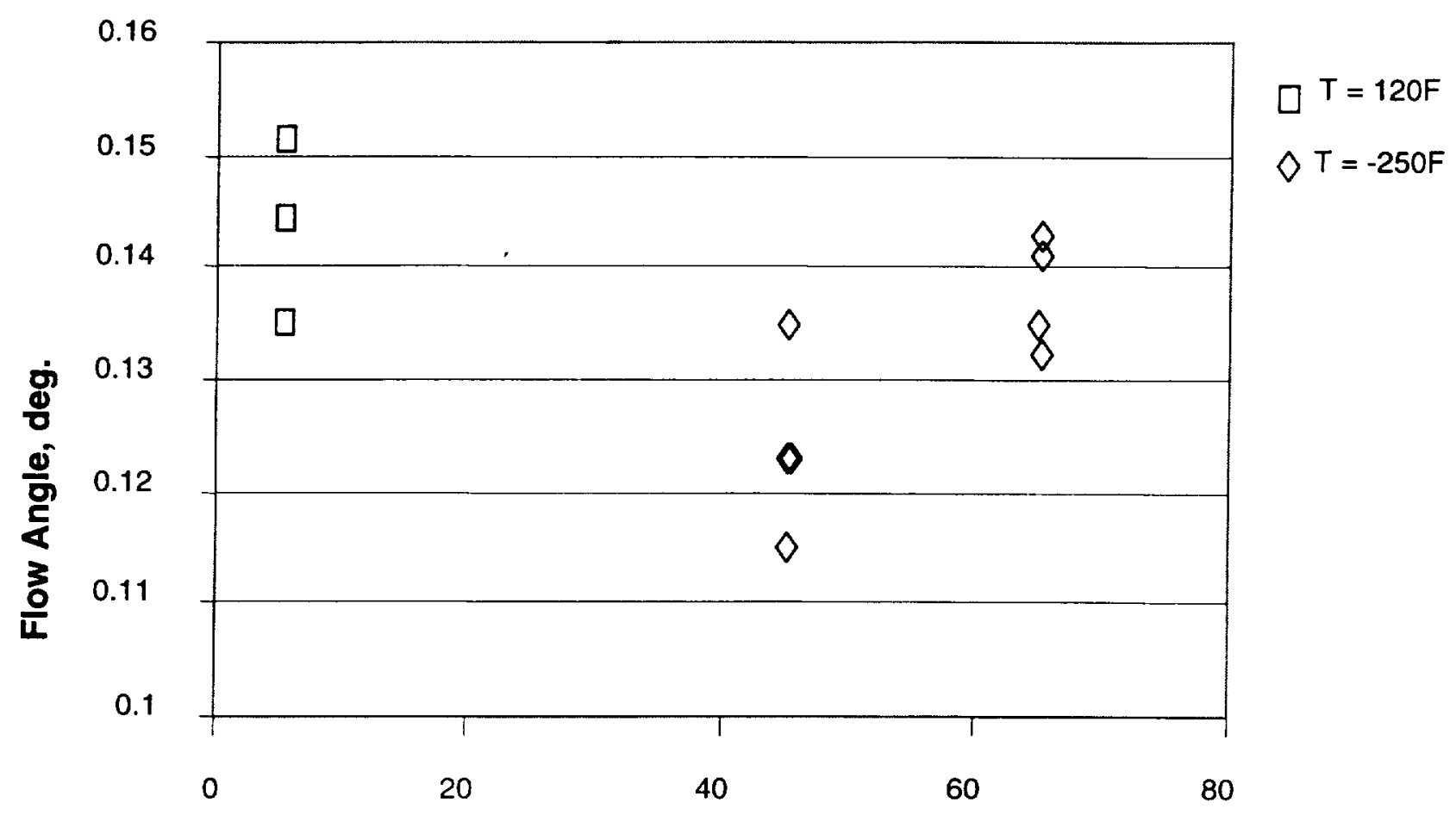

Reynolds Number per foot

Figure 5 - Flow angle variation at $\mathrm{M}=0.70$ over a range of Reynolds numbers 


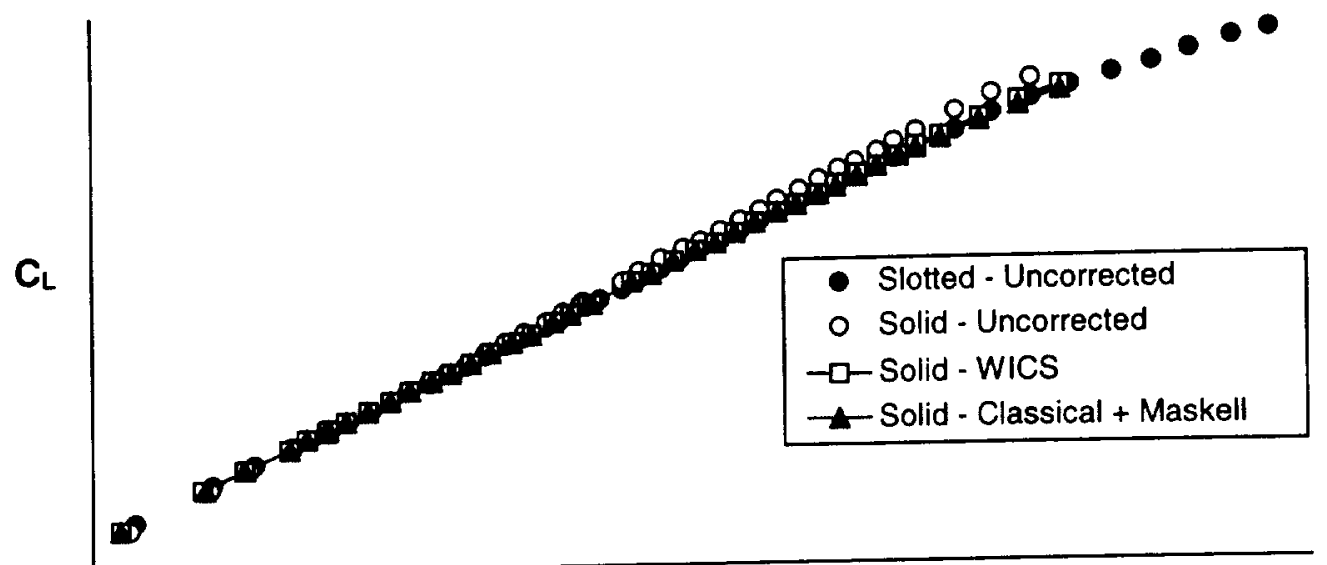

$\alpha$

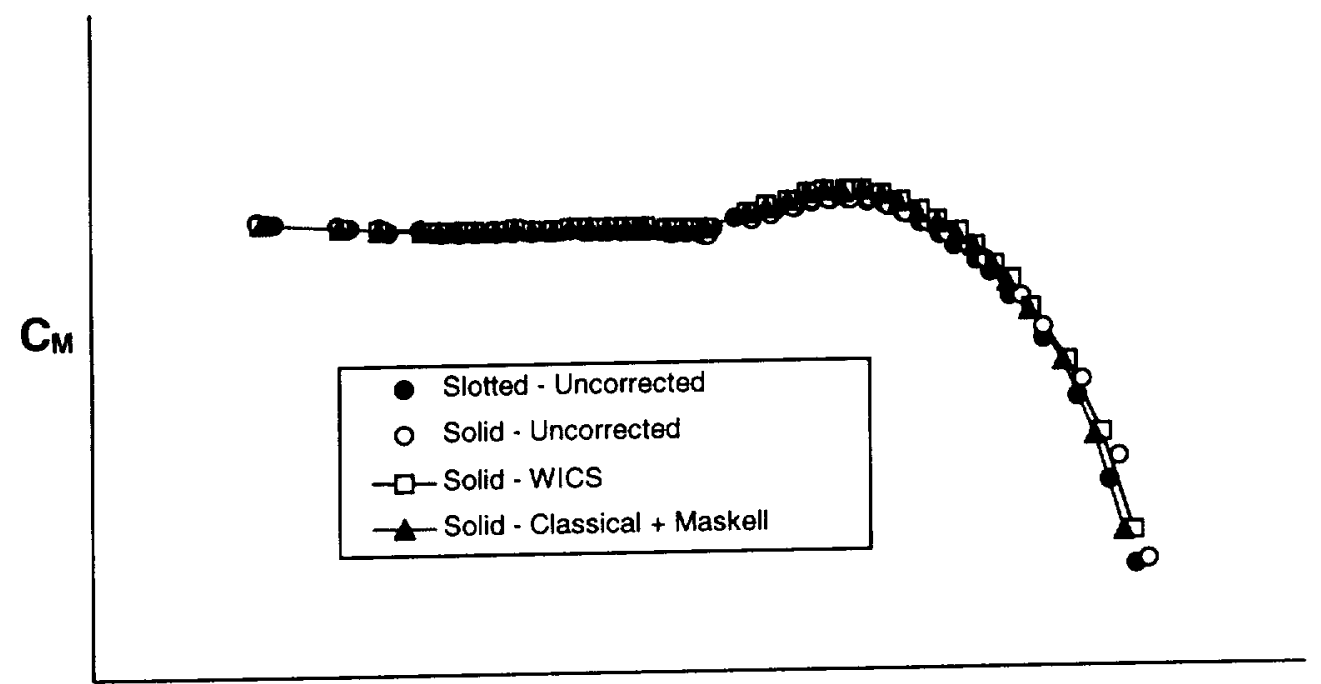

$C_{L}$

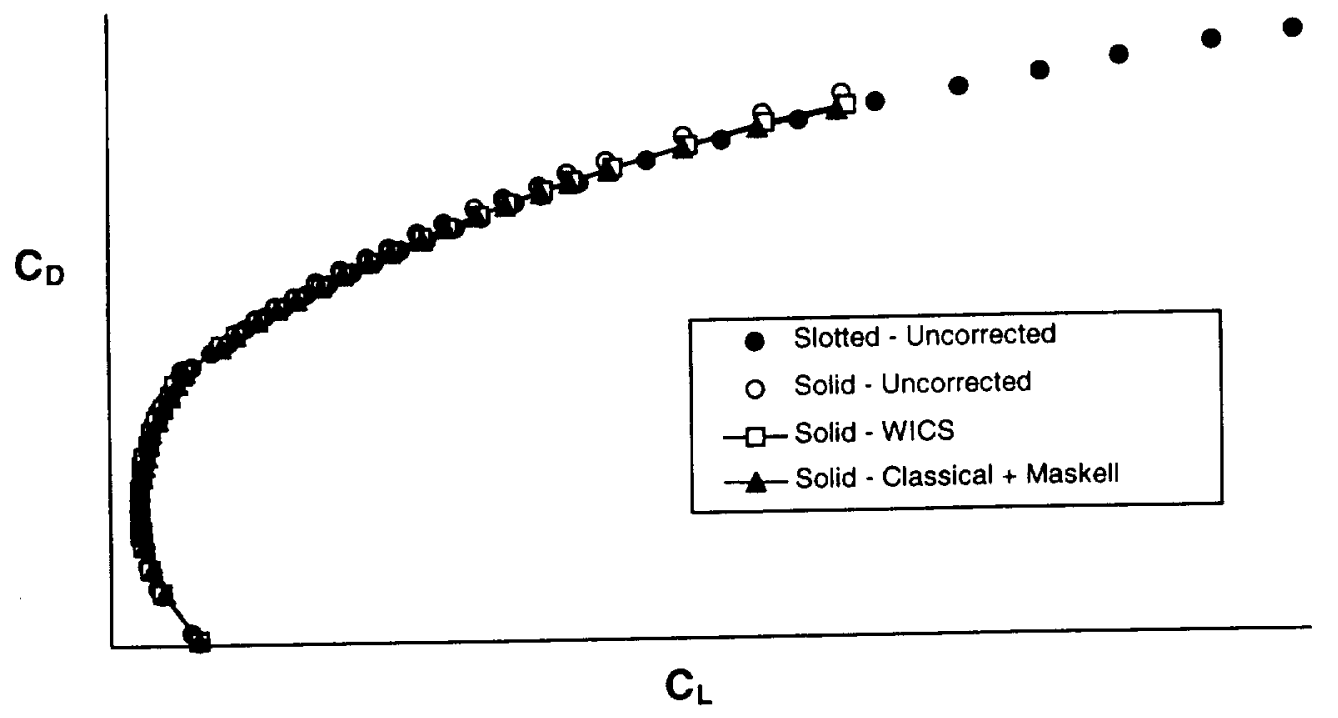

Figure 6.- Low-Aspect Ratio Wing Model in the NTF at $M=0.20$. 
AIAA-2001-0755

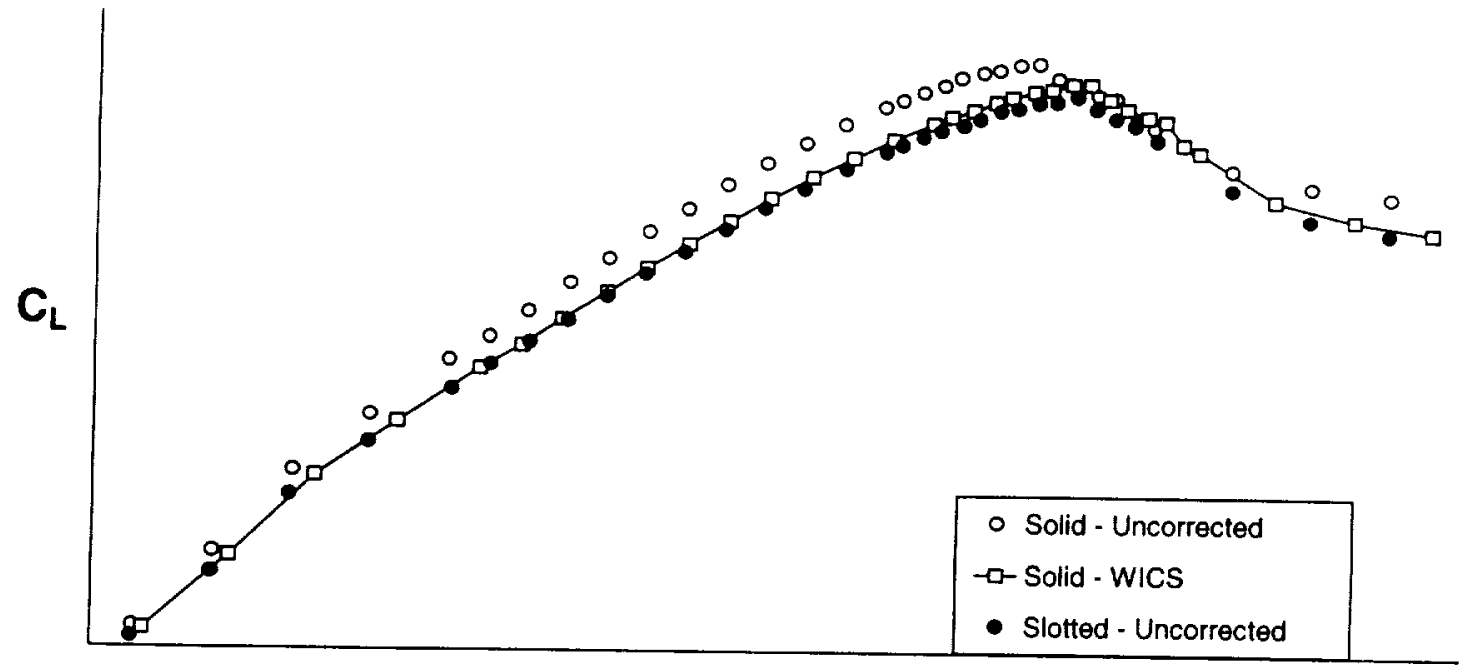

$\alpha$
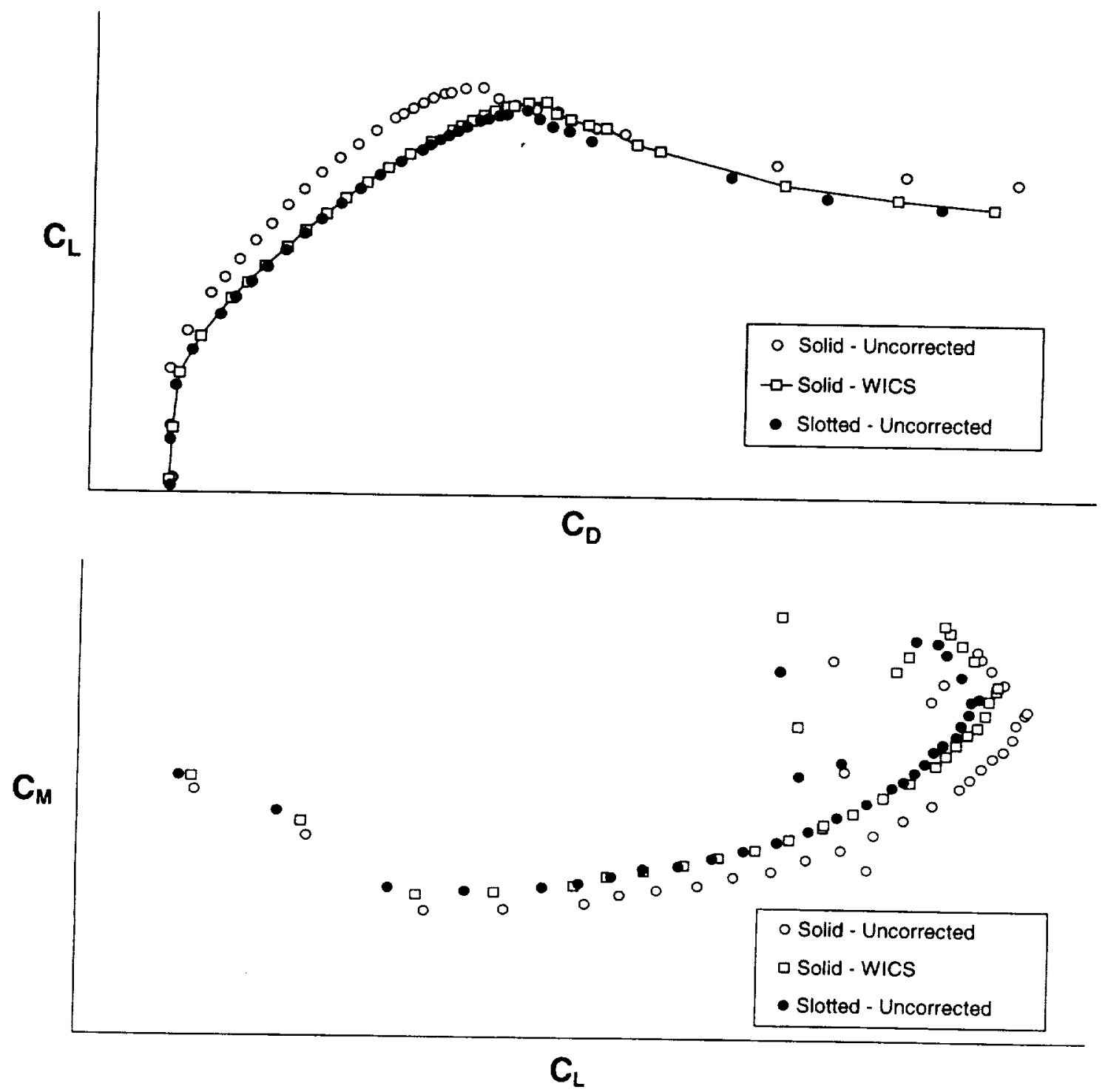

Figure 7.- High-Aspect Ratio Wing Model in the NTF at $M=0.20$ 
